Mariano Latorre.

\title{
MARIMAN Y EL CAZADOR DE HOMBRES
}

(Del libro Tierra de Conquista)

A L sentarme en $\mathrm{mi}$ escritorio aquella tarde calurosa de verano, una invencible modorra cerró mis párpados y me sumió en deliciosa inconciencia. Debí dormir mucho tiempo, la cara sobre un montón de notas y papeles. $\mathrm{Ni}$ un ruido turbaba el silencio de la enorme barraca de madera que hacía de Cuartel de Carabineros. Una hora antes, bajo el bochorno de un mediodía del sur, atravesé las calles de Temuco, pegándome a las paredes para librarme de este aire espeso, que recalentaba el soplo de fuego de los roces. Intenté leer. Mis ojos se cerraron sobre el libro. Una sordina de insectos, en el horno del patio, se adhirió a mis oídos con la invisible sutileza del polvo en suspensión. Me despertó sobresaltado el choque de mí sable, contra los palillos de la silla. En el rectángulo de la puerta, que recortaba la densidad del aire estival, un soldado esperaba respetuosamente que me despabilase.

- ¿Eh? ¿Qué hay?

- Llaman con urgencia de la Comandancia, mi Teniente.

Una torpeza oscura enredaba aún mi atención. Me 
pareció que el teléfono había acunado con su repiqueteo insistente toda mi siesta sobre la silla.

- ¿Quién llama?-pregunté.

$\mathrm{El}$ carabinero respondió sin vacilar:

Conocí la voz de mi Comandante, mi Teniente.

Me puse en pie de un salto. Acudí al teléfono.

Pertenecía al Cuerpo desde hacía un año. La muerte repentina de mi padre me obligó a abandonar mis estudios de leyes e ingresé (era el único medio de ganar pronto un sueldo) a un curso de aspirantes. No tenía una verdadera vocación, pero mi amor propio se tranquilizaba al considerar que es difícil tener vocación para una cosa semejante.

-Aló, aló-dijo una voz impaciente-- ¿Con el Capitán Alvarez?

Era la voz atiplada, casi infantil, del Mayor Chávez.

Contesté:

-No, mi Comandante, mi Capitán salió ayer a Lautaro en comisión del servicio.

- ¿Con quién hablo?

- Con el Teniente Reyes, mi Comandante.

- ¿No hay otro oficial ahí?

-No, mi Comandante.

Oí frases furiosas. Chávez hablaba animadamente con otra persona que no conocí. Mi corazón palpitó acelerado. ¿Habría comprendido aquel gordinflón vulgar mi poco interés por la carrera? Pero sabía lo que era preciso contestar en estos casos. Resonó de nuevo la voz de Chávez. Según su costumbre, intentaba dar a sus palabras vulgares una trascendencia que no tenían. Todas sus frases adquirían una curiosa entonación de arenga militar, aunque no viniese al caso.

-El Intendente me comunica que anoche han asaltado a unos indios, a legua y media de Boroa. El Jefe de Estación necesita fuerzas, porque en la Boletería hay mucho dinero. La partida la capitanea 
Marimán, el mismo que asaltó la estación hace dos años.

Esa personalidad mecánica, defensora del sueldo, que uno va adquiriendo poco a poco en la vida, se despertó ante estas palabras solemnes. Y respondí, envalentonado con mi súbita decisión:

- Puedo ir yo, mi Comandante, en su persecución. El foragido no debe escaparse esta vez. Marimán tiene cuentas pendientes con el Cuerpo, mi Comandante.

-Bien, Teniente Reyes. Salga inmediatamente con los hombres disponibles.

No había perseguido nunca cuatreros, salvo en mis años de aspirante, cuando hacíamos el servicio de patrullas por los caminos de los alrededores de Santiago y buscábamos en ranchos y escondrijos a los maleantes que el paro de las salitreras esparció por los campos. Fuí destinado, más tarde, a los ferrocarriles y en los andenes de las estaciones del sur mi papel fué más bien el de un detective o el de un guardia, porque no era labor muy complicada hacer soltar la verdad a un maletero o llevar a la oficina del Cuartel a alguna muchacha escapada de su casa.

Mediante las viejas prácticas policiales del cabo Soto la verdad salía de los labios temblorosos de la muchacha o se colaba refunfuñando entre los dientes del ladrón.

Grité enérgicamente hacia la cuadra:

-iSargento Suárez!

Apareció el sargento abrochándose la guerrera. Se cuadró en el filo del corredor. A contraluz, con un fondo vibrante de sol, casi no ví su cara, pero su figura alta, huesuda, se recortó con nítido contorno. Precisé, luego, su nariz, torcida a la izquierda por no sé qué accidente de equitación. Prestaba a la cara larga algo de hosco y divertido a la vez, de cómico y de temible. Un bigote espeso cortaba con una línea 
negra, mal trazada, aquel rostro aguzado como el filo de un cuchillo.

¿Cuántos hombres disponibles hay en el Cuartel? Necesito tres para salir a Boroa en comisión del servicio.

Resonó la voz ronca del sargento, su voz habitual: - Sólo hay dos carabineros disponibles, mi Teniente. - Con los dos, entonces-repuse.

Sentí, en el patio, voces de soldado y patadas impacientes de caballos. Fuí a la pieza de armamento a repartir municiones. Al retornar a la oficina, las mantas de Castilla estaban ya enrolladas en los borrenes de las sillas: Los soldados, listos.

Media hora después galopábamos por el polvoriento camino conquistado a la selva. Negrea aún en las hoyadas y su trama de quilas y de boquis se entreteje por las colinas y festonea los arroyos.

El piquete se agrupó, sin orden alguno, en parejas. Los soldados adelante. El sargento más atrás. Yo, solo, a alguna distancia. Miraba con deleite ese mar de lomas gredosas o azules, donde un árbol quemado abría sus muñones deshecho o bebía luz un trigal maduro, tendido en los faldeos. Había olvidado que perseguía a un cuatrero temible, del cual no tenía sino vagas referencias. Iba a llamar al sargento Suárez, cuando éste volvió grupas y se acercó a mí. En realidad, era él quién poseía la práctica de la profesión. Veinte años en el sur, persiguiendo bandidos, a través de bosques y cordilleras, le dieron justa fama de cazador de hombres, de rastreador implacable de huellas humanas. El me dió las primeras noticias sobre Marimán. Era un hombre joven, de las antiguas reducciones indígenas de Carahue. Hijo natural, según se decía, de alguno de esos boers andariegos que se 
establecieron en las cercanías de Pitrufquén y de una de las mujeres del cacique Marimán, que aún vivía, en una hijuela cercana a Boroa.

- Por eso será medio colorín-explicó, apuntándose su nariz, índice severo de sus actitudes.

Suárez era un producto neto de la ordenanza. Las cualidades humanas habían desaparecido, o mejor se habían transformado, en sus pesquisas por el sur, en agresividad hacia todo lo que no fuera uniforme militar o autoridad de la que él dependiese. Y Marimán, para él, no era un delincuente al cual debía aprehender sino un enemigo personal que interrumpía sus quehaceres de cuartel y por esta causa, debía pagar su audacia con su vida.

-Difícil es que lo encontremos, mi Teniente, porque cuando éste asalta o roba animales se aleja de Temuco. Se va a Máfil o Puerto Montt y allí se pone a trabajar con otro nombre. Por la cordillera o por la costa ha de galopar ahora.

Torcióse su boca con un elástico gesto de payaso y agregó:

- Pero si lo encontramos...

No terminó su frase. Cambió su tono amenazante y dijo:

-...me lo deja a mí, mi Teniente.

$\mathrm{Y}$ supuse que si el azar nos colocaba frente a Marimán, difícilmente tornaría vivo al Cuartel.

Le pregunté entonces:

- ¿Tiene muchas muertes encima Marimán?

Se ensombreció su cara. Pareció afilarse la nariz corva como una amenaza. Se endurecieron los ojos. - Al pobre diablo que se le encara le mete una bala por nada. A tres carabineros se ha comido ya. A uno le robó una carabina.

Y explicó, después de una pausa:

-Dicen que es hombre educado, que estudió en la Escuela Comercial de Valdivia, con los Padres 
Salesianos. Y empezó a vivir de robos, cuando desertó del Caupolicán, llevándose un rifle Mauser. En Valdivia tiene un proceso. Y se le juntan algunos cuatreros, algún indio ladrón y con eso se deja caer en las casas. Para comer no más, porque estos campesinos poca plata tienen. Para comer y para llevarse alguna muchacha, que después le pasa a otro compinche o las deja por ahí...

Amarilleó la fuerte dentadura del sargento. El conjunto de ángulos que disponían su cara se quebró formando una especie de sonrisa.

- Tiene mujeres por todas partes. Las tontas se van con él muy a gusto. Y las tiene de pensionistas por ahí, en el rancho de algún mapuche o en la casa de la madre. No hace dos meses se llevó a una hija del Maestro Pérez, de Padre Las Casas.

Noté un tono especial en estas últimas palabras. Un tono de ensordecimiento. Adiviné lo que pasaba por su cerebro en ese instante. El sargento conocía a esta muchacha raptada por Marimán o que, según todas las probabilidades, se escapó con él. Y nada tenía de extraño. Es la vida de los soldados en el sur. A veces, las muchachas mestizas coquetean con el bandido o con el soldado que se acercó al rancho en su persecución. Y con frecuencia, el negocio consiste en estar bien con ambos y a ambos concederles sus favores, según las circunstancias.

Pregunté a Suárez:

- ¿Usted conoce personalmente a Marimán?

- Sí, mi Teniente. El año pasado lo perseguimos con mi Capitán Azócar, por este mismo tiempo de cosechas. Es la época en que saltea. Lo encontramos cerca de Cunco y se nos enmontañó. Se metió entre unos quilantares y de ahí disparó de mampuesto. Cayó entonces el cabo Ramírez con una bala en el cuello.

La idea de que Suárez era el rival de Marimán no 
se apartó de mi atención. No me atreví, sin embargo, a interrogarlo. Consulté el reloj. Eran las tres de la tarde. El chirrido de las chicharras exteriorizaba el hervor del aire, maduro de luz. Lomas bajas, doradas de trigales, o vegas verdeantes de papas caracterizaban el paisaje. Unos hualles finos, elegantes, elevaban el fresco verdegay de sus plumeros, sobre el perfil de las curvas lomas. A ratos, trigales, árboles y vegas bailaban una danza inquieta en el aire removido por el calor. Media hora galopamos en el lomo de las colinas. Blanquearon las calaminas de la estación de Boroa a la distancia. Geométricas cercas de tranquilla, restos de la selva derribada, separaban los cuidados potreros de engorda. Bajo un roble viejo, aun en pie, dormitaban vacas obesas o caballos de redondas ancas.

Nos detuvimos en el patio de la estación. Nos confirmó el Jefe sus sospechas. El día anterior vió bajar a Marimán, con dos individuos emponchados y una mujer. Uno de los acompañantes era Segundo Morales, viejo cuatrero del sur. Los esperaban, pues montaron a caballo y partieron al galope por el camino de Nueva Imperial.

Flaco, de nariz roja, el jefe de estación. Sus frases precipitadas, sus gestos nerviosos no me gustaron. Me pareció que abultaba los hechos para darse importancia.

- Un indio de las cercanías-explicó-vino a quejarse de que unos desconocidos le habían robado una gallina y que uno de ellos le echó el caballo encima al reclamar su precio. Sin embargo, en su propia casa se comieron la cazuela.

Suárez lo escuchó impasible. Su impresión sobre el jefe debió coincidir con la mía, pues le preguntó: - ¿Cómo conoció usted a Marimán?

Respondió con un despectivo frunce de los labios. - iPero si ha pasado doscientas veces por aquí! 
Aunque tenía la barba muy larga y el sombrero le tapaba la cara, lo conocí en el modo de andar, medio pierni-abierto. Y la mujer, una muchacha morena, la he visto con él varias veces, en el tren y en los caminos.

Nos despedimos. Otra vez sobre la carretera, tostada de sol. Miraba a Suárez. La inmutable energía de sus facciones me irritaba. No sé por qué. Quizá por no entender su odio al bandido. Quizá por creer que lo arrastraba un mezquino impulso de venganza o de rivalidad. Quizá por mi carencia de aptitudes policiales. Y recuerdo ahora que siempre en las pesquisas que dirigí estuve calladamente de parte del malhechor. Admiraba, sin poner en ello intención, su heroica independencia, y parecíame desproporcio.nado castigo la muerte o el presidio para estos hombres que, durante los inviernos lluviosos del sur, carneaban animales por hambre y sólo se defendían cuando se les atacaba.

Sería el sol, el polvo que, humedecido de sudor, se endurecía en torno a los párpados, lo que me ponía fuera de mí, obligándome a evitar la mirada de Suárez. Molestábame el que tomase la cabeza del piquete y decidiese de la dirección que debíamos llevar en cualquier cruce de caminos como el recuerdo de su interrogatorio al jefe de estación, en Boroa, sin mi autorización. Se detuvo, repentinamente, en el extremo de la meseta.

Inmenso, de un azul ligeramente rojizo, se hundía el cielo tras la franja oscura, empapada de siesta, de lejanos manchones de selva.

Deliberamos bajo el sol. Según los datos del jefe, Marimán debía hallarse en la casa de su madre, a la margen opuesta del Cautín. Suárez había logrado identificar al otro cuatrero que lo acompañaba por los datos de uno de los carabineros, antiguo soldado de la policía de Cunco. 
-Estos preparan una grande, mi Teniente-comentó el sargento.

- Sobre todo ahora que los cosecheros han traído. la plata al campo-agregó el carabinero.

E hizo, sin que le preguntaran, una biografía de "El Tuerto». No había cometido ningún crimen ni nunca presentó combate a los carabineros. No se comprometía en su oficio de cuatrero. Casi no era un bandido sino un hombre a quien la suerte iba empujando, poco a poco, à una vida irregular. Y se ponía al amparo de Marimán, que llevaba siempre la parte arriesgada de los salteos. Sus asaltos rápidos, sus fugas fulminantes lo salvaguardaban, porque los carabineros, deseosos de encontrar a Marimán, olvidaban a sus cómplices.

Suárez puso término a la conversación.

- Esta vez ni El Tuerto ni Marimán se escapan. - Si los encontramos-apuntó con sorna el soldado.

Pusimos otra vez al galope los caballos. Las rucas de indios, que asomaban sus techos pajizos detrás de las lomas, parecían solitarias. El estrépito de cascos y de sables los hacía ocultarse en los espesos matorrales de las hondonadas. $Y$ sólo sus perros, de extraños pelajes, nos salían al encuentro, ladrando, enloquecidos.

Golpeamos en la puerta de una ruca. Apareció por detrás del rancho un indio viejo, con una barba de conquistador. Nada se pudo averiguar. Respondía con monosílabos. Su cara redonda, imperturbable, daba la impresión de no comprender. En otra ruca, fué una india de chamal la que nos recibió. Ningún indicio.

- Si éstos se hacen los mutres-comentó el carabinero nuevamente.

La nariz de Suárez se torció agresivamente hacia el soldado. Pero nada dijo. Era necesario vadear el Cautín, que plateaba a lo lejos, cortado por redes de 
árboles y jorobas de cerros. Insinué a Suárez la vuelta a Temuco. En realidad, venía pensando en ella desde que salimos de Boroa.

Usted me ha dicho, sargento, que Marimán, después de un asalto, se aleja del lugar donde ha robado. Si es así, debe galopar en dirección opuesta a su casa, ahora mismo.

Sus facciones se endurecieron al oír mis palabras como si las tallase una repentina fuerza interior. Saltó por encima de $\mathrm{mi}$ inexperiencia, con respetuosa cortesía:

- Creo, mi Teniente, que debemos llegar hasta la casa de la madre de Marimán y allanarla. No podemos volver al cuartel con las manos cruzadas.

Sus palabras, impregnadas de viejo respeto a la autoridad, me amedrentaron. Y la noción del deber, el temor al castigo, fueron en mí entonces tan vigorosos como en mi subordinado.

Continuó nuestro galope por la falda de las lomas. Subimos al paso una colina barbechada, bajamos de nuevo. Una faja de agua verdi-oscura, silenciosa, como si se hubiera disuelto en su pereza el alma de la selva donde nació, partía la gracia del vallecito engastado entre colinas; sementeras de oro, verdeantes papales, barbechos oscuros, grises excrecencias de rucas decoraban las márgenes boscosas.

Al llegar a la orilla supimos por un muchacho indígena que el vado estaba una legua más abajo. Era preciso atravesarlo en ese punto, sin embargo. Uno de los carabineros se metió desnudo en el agua. El caballo nadó sólo unos segundos. Y cruzamos el agua espesa, aceitosa, calladamente convulsionada por remolinos traidores que se engarfiaban a las patas de los caballos, haciéndolos resoplar asustados.

Nuestro instinto, es decir, el del sargento Suárez no nos engañó. Ibamos en la buena dirección. Así nos lo confirmó el propietario de aquellas tierras que 
presenció, de pie en la ribera opuesta, nuestro paso por el río. No olvidaré su típica figura de huaso, con un fondo de árboles quemados, que retorcían, en suplicantes actitudes, sus gajos rotos. No lo olvidaré, a pesar de haber encontrado muchos semejantes, mientras permanecí en el Cuerpo de Carabineros. No era un hombre del sur sino un huaso del norte de Chile, trasplantado. Algo así como un mayordomo de fundo del valle central. Cuerpo obeso, largas piernas de torpe andar. Una gran cabeza cetrina. Una franjita roja era la frente entre el espesor de las cejas y el matorral negri-blanco de los cabellos. Cómicamente recortada, una barbita en punta remataba su cara. No había perdido sus atavíos de huaso nortino: chaqueta blanca, con dos rinaleras de botones atrás, pantalones bombachos, zapatos con tacón alto, con aletas sueltas y gastadas.

No contestó una sola vez en forma precisa a mis preguntas o a las del sargento Suárez. No me asombré por esto. Estaba ya suficientemente ejercitado en el trato de estos hombres de la frontera. No quería comprometerse en la pesquisa ni dejar de servir a los carabineros. Así eran todos los colonizadores obligados del sur. Cuatrero al llegar a estas tierras inexploradas y sin vigilancia, cómplice al posesionarse de los campos que recorrían, como reyes y señores, los bandidos y mapuches alzados, enemigo feroz, una vez dueño de las hectáreas robadas, con dinero en Temuco y con influencia entre los políticos, ladrones de todos los tiempos.

En un comienzo trató de poner obstáculos a nuestra marcha. ¿Sería un escrúpulo de solidaridad hacia Marimán que empezaba su carrera de propietario cuando él había llegado ya al término de su esfuerzo? No era eso. Era sólo miedo a comprometerse. Trató de demostrar su desconocimiento de las correrías de Marimán, riéndose del cuento de sus salteos. Fueron 
sus palabras. Suárez le apuntaba su nariz, entre malicioso y molesto. El conocía, también, a estos huasos inescrupulosos y ávidos.

Aceptamos, sin embargo, el asado que nos ofreció.

- Vamos a demorarnos una hora por lo menoscomentó Suárez:- pero es necesario comer por si acaso.

Bajo la frescura de algunos pinos, junto a la casa, lo devoramos. La chicha de manzana, agridulce corazón de las pomas semi salvajes, desató la lengua de don Celindo Gómez, dueño de tres mil hectáreas de tierras limpias, a orillas del Cautín. Era entretenida su verba campechana. Habló de pasados tiempos. De Trizano, por ejemplo, a quien conoció. (Pensé de nuevo en cuatreros y encubridores.) Con nostálgica admiración ponderó don Celindo la habilidad del célebre gendarme, su implacable astucia y su romántico respeto al bandolero austral, aunque lo fusilase por la espalda en cualquier recodo del camino si no se sometía a sus designios. Suárez comía sin mirarlo. Conmigo tomó inesperada familiaridad. Su instinto debió indicarle mi impericia en estos menesteres. Su manaza tosca descansó muchas veces en mi hombro:

- ¿Y tienen la culpa los cuatreros, mi Teniente? Los malos gobiernos, los hombres que no ven, esos son los responsables. Gentes antiguañas cuentan de esos soldados del 79, de esos presidiarios que formaron un batallón y que el Congreso quiso encerrar de nuevo en las cárceles. Apenas lo supieron, se largaron para el sur y ahí tiene usted el cuatrerismo que Trizano ahuyentó. Los de hoy son niños de teta comparados con aquellos.

Estas palabras mesuradas y razonables alejaron de mí la idea de un don Celindo cuatrero o encubridor, ocultando bandidos, a quienes vendía su protección 
por animales robados a los indios o a los colonos establecidos en la región.

-El Gobierno debió encerrarlos sin decirles nada o emplearlos en alguna parte. En el mismo Ejército, por ejemplo. Porque hay que pensar, mi señor Teniente, que eran soldados y que muchos murieron en defensa de la patria. ¡Y mire, tener que formar otro ejército para concluirlos!

Su fuerte dentadura desprendió un fibroso pedazo de carne, masticó unos segundos, bebió un vaso de chicha y comentó con cierto cansancio melancólico:

- Hoy no. Se acabaron los bandidos. Unos cumplen condenas. La mayoría están enterrados en los caminos o en cementerios de indios.

Pero al preguntarle sobre Marimán, dejó escapar algunos detalles que hicieron levantar la vista a Suárez. No lo conocía precisamente. Lo había divisado de lejos, una vez, en unas trillas, porque el padre era vecino suyo. No sabía si estaba en su casa, pero podía estar.

Suárez se había puesto de pie. Con displicentes chupadas fumaba su cigarrillo ordinario. Don Celindo lo miraba de reojo, a través de sus pupilas soñolientas.

-Ese perro se comió dos carabineros-estalló-. Otro no se ha de comer, aunque se esconda debajo de la tierra. Y si llego a encontrarlo, vivo no pasa por aquí.

Sentíme, en medio de este drama, un simple elemento decorativo, impuesto por el Reglamento. A lo sumo, el burócrata que redactaría el parte y daría forma legal a los hechos.

Pero intervine con dignidad profesional:

- Si Marimán se entrega no tiene por qué no venir vivo, sargento.

Miróme con asombro en un comienzo; luego, sonrió. Parecióle bien que defendiera el buen nombre del 
Cuerpo ante este ricacho burlón. Ordenó a los carabineros que montasen.

Don Celindo, desabrochado el chaleco, tirante como un tambor la redonda panza, dirigióse a mí con un tonito zumbón:

-Es mucho hombre este Suárez, mi Teniente. Nos despedimos. Nos daba, solícito, detalles para llegar a la casa de Marimán.

-El camino los lleva solo. En un cerrito, p'al sur, tá el rancho. Por más señas, hay un trigal en la falda. Y acercándose, me susurró al oído confidencialmente, la mano en el anca de mi caballo:

- Calladito hay que entrar, mi Teniente, porque estos 'tan siempre listos.

- No hay cuidado, don Celindo, Se tomarán las precauciones debidas.

Volví a desorientarme sobre don Celindo. No terminaría de conocerlo nunca. ¿Sabía o no de los cuatreros de Boroa? ¿Deseaba o no que los carabineros terminasen con ellos? ¿Era el antiguo encubridor o el propietario actual el que asomaba su cabeza de zorro a través del color de sus palabras y hacía guiños en la malicia de sus ojos, escondidos entre relieves de grasa rojiza? Los azares de una vida aventurera, a ratos cuatrero y a ratos hombre de orden, habían hecho nacer en su cerebro maravillosos recursos de simulación y de mentira. La astucia se había hecho en él inteligencia vivísima, a pesar de su corpachón obeso, adobado por las comilonas y la chicha de manzana.

$Y$ estas reflexiones tuvieron en mí inesperada reacción. Me sentí con una responsabilidad. Era necesario un carácter recto en medio de estas naturalezas huidizas. Y terminé por reírme de mí mismo. A fuerza de repetirse, en la escuela o en el cuartel, ciertas ideas generales sobre la rectitud y la moralidad de un oficial, 
iban echando raíces en mí y determinando mis actos sin que yo interviniese en ellos.

Penetrábamos en una tierra salvaje. El camino lo constituían huellas de carretas que, durante años, siguieron el nivel de las colinas y modelaron con sus ruedas la carretera en la dócil greda de los declives. Enormes troncos carbonizados trazaban en el cielo claro ángulos y curvas inesperadas; otros abrazábanse en el suelo y en los claros; pujante, verdeaba el pasto natural o se erguían las varillas simétricas de las quilas.

En la curva de una loma se estompó la silueta de un indio, en su caballejo tobiano. Suárez se adelantó a interrogarlo. No entendió sus palabras o fingió no entenderlas. Repetía estúpidamente:

- ¿Ruca? ¿Marimán?

Hubo que dejarlo. Nuestra aparición repentina lo anonadó, pues volvimos a verlo un cuarto de hora después en el mismo lugar, enclavado en la cumbre, como una estatua de la degeneración araucana, en su caballo dormilón, a grandes manchones claros y su facha deplorable de mapuche pobre. Subimos una nueva colina barbechada. Apareció otro vallecito. Un estero debía cruzarlo, porque dos cordones verdinegros de boldos y pilos señalaban claramente el fluctuar de las aguas en los altibajos del terreno. El sendero nos llevó como un guía hasta el vado.

Uno de los carabineros, que se había adelantado por orden de Suárez, vino a nuestro encuentro. Acababa de localizar la casa y el trigal, en el extremo del valle. Nos detuvimos en un espeso bosque de temos. Desmontamos. Por consejo de Suárez nos internamos algunos metros entre los árboles. Discutimos el plan de ataque. Como era lógico, dejé obrar al sargento. Desde luego, la tropa iba a desplegarse alrededor de la casa para cortar la retirada de los bandidos o de cualquier persona que intentase subir la cumbre 
y pasar al otro cajón. Uno de los carabineros, cruzando el bosque de la derecha del camino, debía situarse detrás de la casa. Veo aún el caballito negro que montaba, «El Tordo», ágil, nervioso, apareciendo y desapareciendo por entre los matorrales, abierta su cola a cada contacto de la espuela, como un corcel de guerra. Por última vez.

Suárez me dijo, entonces:

Usted, mi Teniente, debe resguardar el bajo. Se divisan una serie de coigües, para el lado donde va el estero. Yo subo por el lomo de este cerro con el dragoneante Martínez.

No me mezclé para nada en sus disposiciones. Ni siquiera por fórmula le hice observación alguna. Su pasmosa seguridad me subyugaba. En ese momento era el prodigioso resorte de un mecanismo sabiamente disciplinado. $\mathrm{Ni}$ temor ni reflexión en su actitud. Y pensé que si la muerte salía a su encuentro en la eventualidad del combate serían idénticos sus movimientos y sus palabras. saludo.

- ¡Hasta luego, mi Teniente!--dijo con afectuoso

Se perdieron rápidamente los caballos entre las innumerables acumulaciones de temos y de pilos. Me encontré solo en medio de los árboles. Me sobrecogió un supersticioso amedrentamiento. No era miedo, pero el vuelo de los tordos y lloicas o el rápido frufrujeo de las hojas me estremecía con un largo escalofrío. Sin la sugestión disciplinaria del sargento mis ideas sobre los cuatreros volvieron a posesionarse de mi sensibilidad. Un gesto de asco secaba mi garganta. Resolví en mi interior vegetar de furriel en las oficinas de un Cuartel de Carabineros de provincia, antes que perseguir a un hombre de mi raza en resguardo del ricachón ávido del sur, más peligroso para el porvenir de Chile que el desgraciado mestizo al cual arrinconábamos en ese instante. Me alivió la idea de que 
Marimán pudiese haberse escapado, si estaba en la casa.

Con el caballo de tiro seguí el sendero trazado entre los árboles. Lo amarré a un pilo en un claro. Y agazapado corrí por entre los troncos hacia el fondo de la vega. Antes de alcanzar un enorme coigüe colocado en el medio del valle, oí el primer disparo. Tuvo un eco estrepitoso en mi corazón. Marimán estaba en la casa. Levanté precavidamente la cabeza. Un hombre alto, con una carabina en la mano izquierda, atravesó corriendo la explanada que enfrentaba las casas y se ocultó entre las altas espigas, bañadas de roja luz. Amartillé mi pistola. Sonaron cuatro tiros casi simultáneos y en direcciones distintas. El puro cristal de aquella tarde de verano se rompió en millones de sonoras trizaduras. Una bandada de torcazas tableteó sobre mi cabeza. Unos indios que araban en las faldas de una loma desenyugaron sus bueyes y se perdieron entre los matorrales. Inmóvil, ensangrentada de poniente, se recortó la casa abandonada, como un pontón a la orilla del mar de oro de la sementera. Las balas agujereaban el aire con un zumbar de moscardones. Apoyada la cabeza en el tronco ví cómo el bandido (no me cupo duda que era Marimán) asomaba la cabeza por entre las espigas y sus disparos se repartían matemáticamente en la dirección de los soldados. Les grité que bajasen de los caballos. Me asombró a mí mismo la energía de mi voz de mando. Una bala hizo saltar la corteza del coigüe en mil esquirlas rojizas. Era la respuesta del bandido, a mi grito de alarma. Comprendí, entonces, cómo protegió Suárez la inviolada seguridad del jefe, designado por el Estado. El estrépito de un relincho colmó como una ola el valle entero. Algo de agonía salvaje, de primitivo tenía este relincho. Ví caer de rodillas dilatadas las narices, al caballito negro. 
- Pedazo de bruto!-insulté al soldado, fuera de mí.

El tiroteo se hizo inteligente, más espaciado y en una misma dirección. No tardé en comprender que Marimán había reconocido a Suárez. Empezó, entonces, un duelo salvaje, astuto, insidioso. Suárez arrebató la carabina del dragoneante, y sin miedo a que una bala lo tocase, disparaba hábilmente hacia el trigo. Marimán hacía lo mismo, desplazándose entre las espigas. Por parte de Suárez, el ataque tenía una agresividad implacable. Advertíase que quedaba en el campo o ultimaba a Marimán. Este se limitaba a defenderse, cercado por todas partes, deseoso de abrir un hueco para escaparse. La muchacha de "Padre Las Casas» no se apartaba de mi imaginación. Suponíala unos segundos chica, aindiada, o bien esbelta y rubia como una criolla alemana. A cada disparo del bandido, Suárez daba un salto de puma, acercándose a las casas. Buscaba el abrigo de un gran roble botado a la orilla del trigo, a modo de cerca. Temí verlo caer de un momento a otro, porque su chaqueta blanca, cruzada por el correaje del uniforme, presentaba un magnífico blanco. Su audacia nos sugestionaba, y cada uno de sus saltos felinos era una orden tácita que todos obedecíamos metiéndonos sin miedo en el trigal. Oigo aún el chasquido de los tallos quebrados y el rodar de los granos rubios, en esta trilla inusitada y mortífera. La complicidad de sus varillas sonoras y radiantes ocultó hasta el último momento el destino de aquel hombre heroico e infeliz.

De improviso, callaron los disparos. En este remanso del silencio, los ruidos del campo se removieron con una tumultuosidad de marea. Asomé precavidamente mi cabeza por la superficie del trigo. Nada se veía. Ni Marimán ni Suárez, pero me agaché con rapidez, porque el bandido podía muy bien 
buscar un blanco más preciso para aprovechar sus últimos tiros.

Oigo, de pronto, una voz quebrada que clama roncamente:

- Toy dao!

Me levanté. Dos brazos toscos, crispados, emergían de las espigas. Avancé por el trigo impetuosamente. Me detuvo un grito del sargento.

-iCuidado, mi Teniente!

Sonó un disparo. Ví describir a una carabina un largo semi-círculo y caer sobre el trigo. Me acerqué. Sudoroso, sin quepís, desabrochada la guerrera, inyectados los ojos, Suárez pateaba en el suelo los despojos del bandido. Se detuvo al verme.

- Esa es la treta. Así cayó Pino en Máfil.

Un resoplido estruendoso nos hizo volver la cabeza rápidamente. La bala del bandido había herido mortalmente a otro de los caballos, un gran alazán, que cayó de lado, encogiéndose en trágicas convulsiones.

Sobre esa alfombra de destrozadas espigas agonizaron juntos la bestia y el hombre. Me incliné curioso sobre Marimán. El grueso belfo crispado torcíase en una mueca de dolorosa rabia. Extraños arabescos de sangre enrojecían su camisa blanca, limpia, recién puesta. Siete balas, según constatamos, atravesaron distintas partes de su cuerpo. Mirábalo con emoción, con una complacencia malsana. La que de niño experimentaba al tener entre mis manos el pájaro que voló inaccesible sobre mi cabeza.

Alto, blanco, expresivo era su frontal, enérgicamente enclavado en los arcos superciliares. Una frente nórdica, alba de serenidad; pero la curva aguileña de su nariz y la saliente redondez de sus pómulos eran mapuches, a pesar de su rojez tostada. Iguales los pelos escasos del bigote y la raleza de su barba cobriza. Era una vitalidad potente la de este mestizo del sur. Vitalidad loca, gastada al capricho del instinto en 
las tierras de conquista. La misma que endurecía el carácter del sargento Suárez y tallaba en acero los ángulos de su rostro acuchillado. Me viene a la memoria una observación que hice en mi corta carrera de Teniente de Carabineros montados, cada vez que el azar puso frente a frente dos hombres del temple de Suárez y de Marimán. Confundíanse psicológicamente, aunque fuese diverso el fin que perseguín y el medio en el que actuaban. El empuje era el mismo, la misma desbordante vitalidad, el primitivo concepto de su misión en el mundo o su desprecio irreflexivo por la vida. Estoy seguro de que si en lugar de Marimán hubiera caído Suárez tendría impreso, en su boca tajante, ese mismo gesto rebelde, y el cuerpo desangrado recibiría, en sus postreros estertores, salvajes patadas e insultos denigrantes.

Corté la repugnante escena, ordenándole a Suárez que me siguiese a la casa para efectuar el allanamiento y averiguar quiénes acompañaron al bandido en ese instante.

No encontramos rastro de los cuatreros que llegaron con él a Boroa. Allí no estaban sino la madre de Marimán y una muchacha morena de bellas facciones. Exteriormente nada conmovía el óvalo morisco de su cara y los almendrados ojos negros, que parecían miniaturas del rostro mismo. Una chiquilla sucia, de mechas rojizas, se agarraba a sus vestidos. Todo esto era aparente. La aparición del sargento comunicó un temblor nervioso a su barbilla puntiaguda, mientras la mano grande, tosca, aferraba histéricamente un pliegue de la pollera, Suárez preguntó con su habitual energía:

¿Quiénes estaban aquí con Marimán?

La muchacha tartamudeó algo que no se entendió. Suárez subió la voz:

- ¡Aquí debe contestarse con claridad y sin mentir! Si no... 
Rompió a llorar la chiquilla con un chillido agudo. De un rincón surgió la madre de Marimán. Acercóse a nosotros amenazante, moviendo vertiginosamente sus brazos cobrizos, gruesos como gajos de árboles. Frases cortas, como rápidas explosiones, salían de su boca tremulosa. Entendíanse algunas palabras en castellano: "icarafinero, matar hijo, perro, carafinero!» Dirigíase a Suárez que la escuchaba atusándose el bigote, caída la nariz en un desplome benigno, pero un repentino grito del sargento estranguló su estridente monólogo en mapuche. No agregó una palabra más, como si estuviera acostumbrada a la violencia de mandatos semejantes. Y Marimán y Suárez volvieron a coincidir en el mismo ángulo psicológico, me parecieron en el mismo plano de agresiva impulsividad.

Pero la escena me irritaba. No era molestia por mi deslucido papel en la caza de hombres, no. Era, más bien, el fluctuar quemante, vergonzoso del deber profesional con las convicciones más arraigadas de mi alma. No podía separar a Suárez de Marimán ni a Marimán de Suárez. Si el bandido hubiese triunfado mi furia iría a él, estaba seguro; pero muerto, Suárez se me aparecía repulsivo, deformada su naturaleza viril por crueles abusos de autoridad. Ambos destruían, con sus pasiones desatadas, el concepto de humanidad que brillaba sin morir, a pesar de mi profesión, dentro de mi conciencia.

Intervine con violencia cuando Suárez volvió a interrogar a la muchacha después de recorrer la casa y el patio trasero. Había descubierto en el huerto los restos de una comilona reciente. La niña no contestó una palabra y Suárez, furioso, la zarandeó rudamente por los brazos.

- Suelte esa mujer, sargento.

$\mathrm{Y}$ ordené envolver el cadáver para llevarlo a Temuco a caballo. La noche se nos viene encima. 
De mala gana debió soltar a la muchacha. Aquellos restos de churrascos, los conchos de chicha que amarilleaban en los vasos y la yerba que aplastaron los cuerpos en indolente abandono, habían exacerbado sus celos, desencadenando todos los fermentos de su animalidad. Fué a levantar el cadáver. Lo hizo con la hábil seguridad de costumbre, pero no cesó de multiplicar las razones para convencerme de que debíamos llevarnos la muchacha a Temuco.

-Vea, mi Teniente, ésta debe saber muchas cosas de Marimán y sobre sus cómplices. No hay que dejarla escapar.

- De escaparse no se escapa, sargento. Ya la haremos venir mañana. Hoy no tenemos caballo ni para nosotros.

No replicó. El mismo puso el cadáver de Marimán sobre el propio caballo del bandido, un caballo rosillo, como espolvoreado de niebla en las ancas y sembrado de leves salpicaduras de alba en las tablas del cuello. No fué difícil cogerlo y embridarlo. Estaba con la silla floja y dormitando, en una cerca hecha con el mismo lazo del cuatrero, en torno a los pilares del corredor. Con él fué atado el cuerpo a la silla cuyana, doblándolo en la cintura.

El llanto agudo de la chiquilla pelirroja y los insultos de la madre de Marimán nos acompañaron largo rato por la hondonada. Uníanse al croar de los sapos en los aguazales y al soplo de los concones, sorprendidos en sus nocturnas correrías. La sombra densa de los matorrales rayábanla miles de luciérnagas, aéreas y azules como partículas de luna extraviadas en el campo. Era preciso ir despacio por estos senderos fluctuantes, llenos de hoyos y salientes. La confianza volvió a reinar entre Suárez y yo, como al principio del viaje. Con generoso desprendimiento trataba de hacer recaer en mí la gloria de la captura y sin darme cuenta (imalhadada defensa de la mensualidad!), 
sentíame aureolado de heroísmo. Le devolví su lisonja, ponderando su sangre fría, su habilidad de soldado.

-Debía usted ser ascendido a oficial-le dijecomo tantos que hay en el Cuerpo.

Me sorprendió su respuesta, ligeramente burlona y sin denotar ambición alguna:

- Pero si esto no tiene gracia, mi Teniente. No hay choco que dé en el blanco a esa distancia. ¿No ve que los cortan más acá de la mira? ¡Cerca, claro que la cosa cambia!

$\mathrm{Ni}$ miedo, ni vergüenza, ni remordimiento. Un recurso del que se aprovechó astutamente para no ser herido. Sin ese choco, es muy posible que Marimán se hubiera escapado. El recuerdo del bandido, en medio del trigo, llenó de nuevo todo mi espíritu. Desangrado, hecha un harapo su vitalidad y su fuerza, marchaba delante de nosotros. Envolvíalo la noche, cuajada de estrellas y luciérnagas, de croar de sapos y de fresco de ocultas corrientes. Con ágil trote caminaba el rosillo de Marimán, como si su mismo amo lo espolease al sentir, tras él, apremiante ruido de cascos. Camino que su instinto conocía: matorrales de clavadoras quilas, gredas resbaladizas, helados pozos de aguas dormidas.

A las nueve de la noche vadeamos nuevamente el río.

Nadie se había dado cuenta de nuestro paso. Sin embargo, el tiroteo debió oírse a tres leguas a la redonda, pero ninguno salió a nuestro encuentro. Un silencio de país deshabitado hacía más sonoros los golpes de los cascos en las piedras y los estornudos de las cabalgaduras. $\mathrm{Ni}$ don Celindo. Su casa de hacendado rico era, en la noche clara, un pesado muro de sombra. Solo sus pinos murmuraron algo al paso de nuestros caballos.

Suárez, que debía sentir hambre o simplemente 
deseo de mostrar el cadáver baleado del bandido al campesino, murmuró con sorna:

- iPor ahí debe estar cachando, detrás de una ventana! ¡No crea que ha dormido con los tiros!

Al entrar al puente del Cautín el caballo de Marimán se atravesó en la calzada y no hubo medio de hacerlo pasar. Implacables resonaron las pencas de los soldados sobre sus ancas. Yo mismo, las golpée rabiosamente con mi látigo. Muchos de esos golpes, a causa de los quites del caballo asustado, debieron caer sobre el cadáver cuyas piernas lacias asomaban en el ruedo del poncho, a ángulos grises y negros, que cubría el cuerpo. ¿Qué era lo que asustaba en esa forma inusitada al caballo? ¿Tal vez las sombras rectas de las casas, mordiendo con sus dentados ángulos el tapiz estrellado de la noche o quizás el lagrimeo de oro de las ampolletas, punteando la llanura como las candelillas en un gualve?

Mi impaciencia se hizo agresiva. A cada instante creía que la muchedumbre nos cercaba y nos pedía cuentas, con amenazantes injurias, de la muerte del bandido.

Le ordené a Suárez secamente:

-Vea si las amarras molestan las verijas del caballo, sargento.

Siempre seguro de sí mismo Suárez respondió una vez más:

-No se han corrido, mi Teniente, pero voy a revisarlas.

Descabalgó calmadamente y recorrió las amarras que sujetaban el cuerpo al lomo del caballo. A un movimiento, vi deslizarse el poncho blanquinegro y por unos segundos (Suárez tapó rápidamente el cuerpo) mostróse la cabeza desgreñada del bandido y la dentadura sólida, enérgicamente cerrada, a causa del arriscamiento de los labios.

$\mathrm{Y}$ de repente, como si se hubiera convencido de que 
era inútil toda resistencia, el caballo echó a andar por el medio del puente.

Suárez me explicó sin que yo se lo pidiese:

Como buen caballo de bandido, nunca entró al pueblo. Marimán lo dejaba por ahí, en cualquier parte, listo para escapar. Por eso mañereó.

Sus palabras me evocaron aspectos inesperados de la vida del cuatrero, en los paréntesis de sus asaltos, cuando, por desconocidas veredas, se acercaba a Temuco, en busca de la moza de turno, mientras el rosillo, salpicado de rocíos mañaneros, dormitaba en el patio de la casa, amarrado a un árbol o a una cerca. Sin saber por qué sentíame liviano, sin remordimientos, como si lo que hubiera pasado fuese sólo un sueño. Ni Suárez ni Marimán me parecieron salvajes $\mathrm{y}$ primitivos. El vigor que demostraron, al pelear a muerte como en tiempos ya desaparecidos, los enaltecía, tornándolos heroicos. $\mathrm{Ni}$ inútiles ni culpables. Productos de su medio, nada más. Fenómeno inevitable en la formación de un pueblo y de una raza.

El rosillo de Marimán trotaba con su fúnebre carga por los adoquines de Temuco. Repiqueteaban las herraduras al chocar en las piedras sueltas del pavimento. Ni un alma cruzaba por las calles. Amarillas ampolletas, veladas de polvo, apenas clareaban el sueño de las sombras.

A media noche llegamos al Cuartel.

Al día siguiente, mientras redactaba el parte, llegó a las oficinas de la Comandancia el Mayor Chávez. Oyó complacido la narración de la muerte de Marimán. Quiso ver el cadáver. Su cara enorme, cuyos rasgos estaban a punto de fundirse en una bola de grasa morena, trasudaba satisfacción. No había hecho 
él la captura ni había corrido riesgo alguno, pero el librar a la comarca de un cuatrero temible sería, para el pueblo, sólo obra de su iniciativa. En una comilona provinciana contaríanse las peripecias del combate y algún antiguo cómplice del bandido, hoy influyente propietario, empinaría un vaso por el fausto suceso de su muerte o por el testimonio vivo de su pasado que desaparecía para siempre.

La manta volvió a cubrir el pálido bronce de la cara, donde los ralos pelos rojizos semejaban vetas de sangre coagulada. Todas las moscas de las pesebreras habíanse trasladado al cuarto y zumbaban impacientes sobre el cadáver. Chávez me felicitó, recitando no sé qué huecas consideraciones sobre el deber y el espíritu de sacrificio. Y es preciso que lo confiese con franqueza: me sentí tontamente halagado por aquellas frases que aseguraban con un sólido remache mi carrera. El sargento escuchó mi narración cuadrado militarmente. Intervino dos o tres veces para rectificar algún detalle o poner de relieve lo que olvidase en el fuego de mi relato. No había en sus rectificaciones ni odio ni vanidad, y, sin embargo, un encono cuyo origen no me explicaba, me iba, poco a poco, envenenando. Creí que hasta se burlaba de mi entusiasmo y sus interrupciones no tenían otro fin que dejar, ya sea en el parte o en la memoria de los que oían, un recuerdo imborrable de la pesquisa. Su resignación de oficial subalterno buscaba así una gloria indirecta y lejana. Mi asistente, un mapuche de Alpehue, que odiaba a Suárez, se encargaría de comunicarme si en la intimidad del rancho o de la cuadra, el sargento hacía alguna alusión burlona a mi actitud y se ponía, como era de suponerlo, en el heroico plano que le correspondía.

Pero ahora yo era el dueño de la situación. Así 
fué que grité, para que Chávez lo oyese, al medio del patio.

- Sargento, que vayan los carabineros a Boroa a descuerar los caballos para instruir el sumario correspondiente.

Desde el otro extremo, bañado de sol, la voz ronca de Suárez contestó:

-Está bien, mi Teniente. 